\title{
Kinetic Analysis of the Antidiuretic Action of Vasopressin and Adenosine-3', 5'-Monophosphate *
}

\author{
Isidore S. Edelman, Martin J. Petersen,† and Paul F. Gulyassy $\vdots$ \\ (From the Cardiovascular Research Institute and the Departments of Medicine and Physiology, \\ University of California School of Medicine, San Francisco, Calif.)
}

Studies of the antidiuretic action of the neurohypophyseal hormones have been facilitated by the development of responsive in vitro systems (anuran skin and bladder) (1-4). On the basis of their findings with anuran skin, Ussing and coworkers $(5,6)$ proposed that the movement of water and small solutes across the skin is limited by porous and diffusion barriers arranged in series and that vasopressin increases the diameter of pores in the porous barrier. Hays and Leaf $(7,8)$ extended the pore theory to the urinary bladder of the toad and concluded that vasopressin enlarges aqueous channels penetrating the mucosal face of the epithelial cell membrane. Evidence obtained by Orloff and Handler $(9,10)$ and by Brown, Clarke, Roux, and Sherman (11) indicates that vasopressin exerts its effects by stimulating the generation of adenosine- $3^{\prime}, 5^{\prime}$-monophosphate (cyclic AMP).

The present study extends the observations of Hollander, Williams, Fordham, and Welt (12) on the kinetics of the antidiuretic action of vasopressin in vivo and those of Karlin (13) on the spontaneous resistance to the action of neurohypophyseal hormones in vitro. For our studies a volume chamber was developed that allows continuous measurement of the net flow of water across the isolated toad bladder. This device was used to characterize the kinetics of the antidiuretic action of vasopressin and cyclic AMP and of combinations of both agents. We have interpreted the results in terms of the pore-cyclic AMP theory.

* Submitted for publication May 19, 1964; accepted July 20, 1964.

This work was supported by grants-in-aid from the National Heart Institute (HE-06285) and the American Heart Association, Inc.

$\dagger$ During the tenure of a Research Fellowship of the National Heart Institute.

$\ddagger$ During the tenure of an Advanced Research Fellowship of the American Heart Association.

\section{Methods}

The glass apparatus used to measure rates of net transport of water consists of an open right-angled cylinder and a closed chamber with an attached 1- or 2-ml pipette (Figure 1). To keep the hemibladders rigidly in place, nylon mesh hose, no. 30 denier, was drawn tightly over the opening of each hemichamber and secured with rubber bands. A rubber gasket was placed between the flange of the glass and the nylon mesh to prevent leakage. The closed chamber and pipette were filled and drained through stopcocks. Water flow for 5- or 10-minute periods was measured by timing the travel of the meniscus in the pipette. The pipettes were calibrated in units of $0.01 \mathrm{ml}$, and the readings were interpolated to $0.001 \mathrm{ml}$. The open cylinder was oxygenated and stirred with an air stream through an inlet designed as an air lift pump. Equal hydrostatic pressures in the two halves of the chamber were assured by calibration of the open cylinder. The area of exposure of the bladder was $3.1 \mathrm{~cm}^{2}$ except for the studies illustrated in Figure 8 in which larger chambers providing an exposed area of bladder of $7.1 \mathrm{~cm}^{2}$ were used.

The composition of the bathing solutions was as follows: Serosal solution A ( $\mathrm{Na}^{+}$Ringer's) consisted of $111.0 \mathrm{mM} \mathrm{NaCl}, 2.4 \mathrm{mM} \mathrm{NaHCO}, 3.4 \mathrm{mM} \mathrm{KCl}, 2.7$ $\mathrm{mM} \mathrm{CaCl}, 5.5 \mathrm{mM}$ glucose, and $2.0 \mathrm{mM}$ urea (osmolality $=0.235, \mathrm{pH}$ in air $=8.4)$. Mucosal solution $\mathrm{A}$

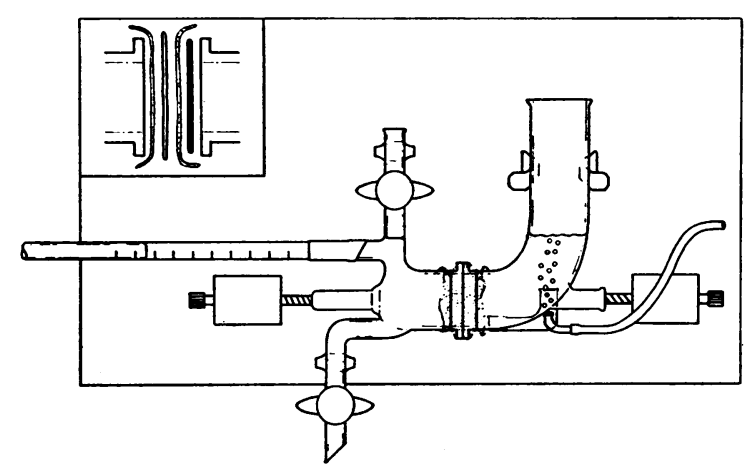

Fig. 1. Volume chamber apparatus consisting of A CLOSED CHAMBER ON THE LEFT, A "SANDWICH" OF NYLON MESH, TOAD BLADDER, NYLON MESH AND A RUBBER GASKET, AND AN OPEN CHAMBER ON THE RIGHT, AERATED AND MIXED BY AN AIR LIFT PUMP AND HELD IN AN ASSEMBLY BY THUMBSCREWS. The inset is an enlargement of the "sandwich." 

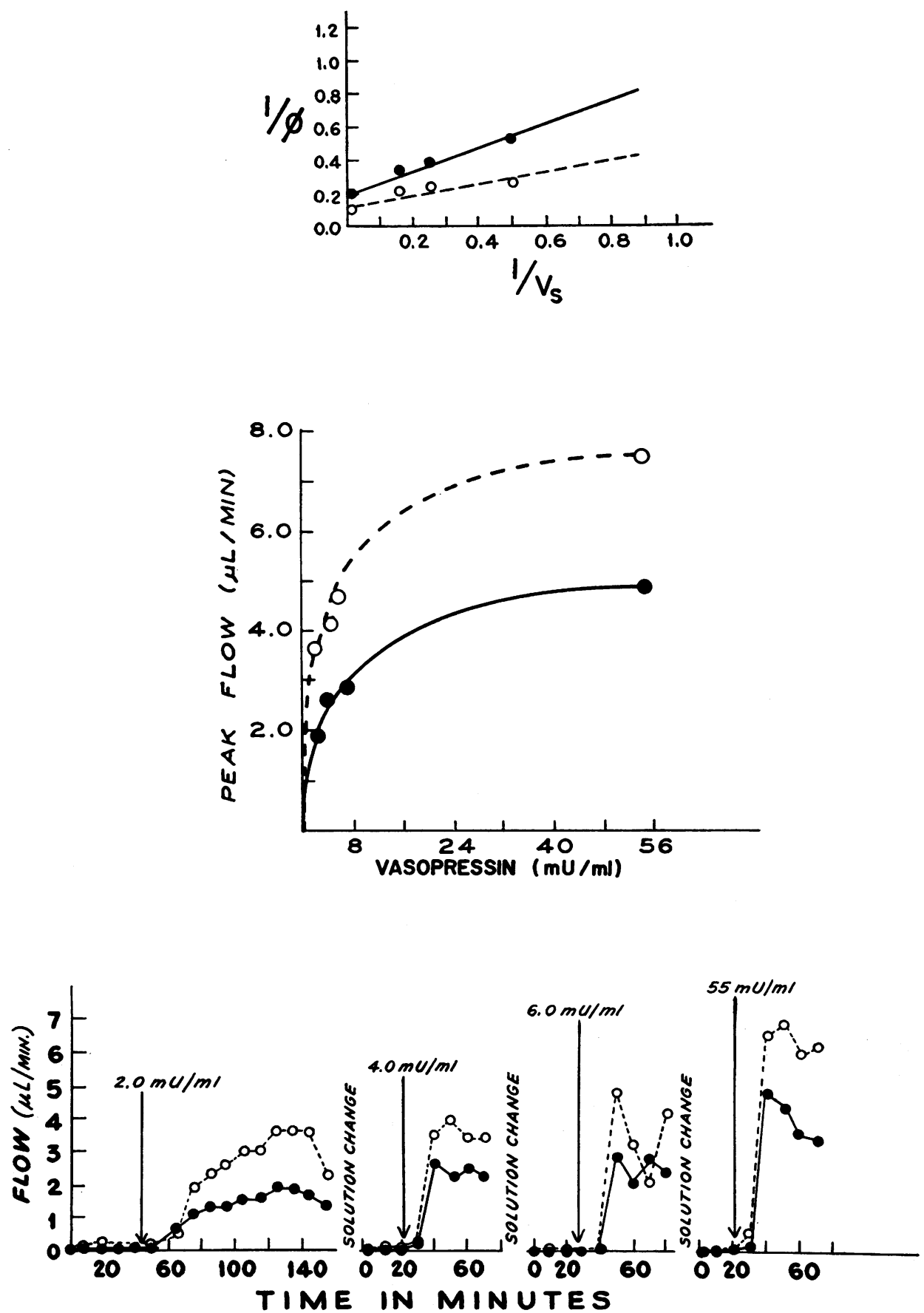

Fig. 2. LOWER GRaPh: THE EFFect OF GRADEd INCREASES IN THE concentration of vasoPRESSIN ON THE RATE OF OSMOTIC FLOW AS A FUNCTION OF TIME. The final concentration of vasopressin in the serosal medium is given in milliunits per milliliter, and the time of addition is indicated by the arrow. MidDle Graph: The RATE of osmotic Flow AT THE PEAK of RESPONSE AS A FUNCTION OF THE CONCENTRATION OF VASOPRESSIN IN THE SEROSAL MEDIUM. Data taken from the lower graph. UPPER GRAPH: THE RECIPROCAL OF THE RATE OF OSMOTIC FLOW AT THE PEAK OF THE RESPONSE (1/ $\phi$ ) AS A FUNCTION OF THE RECIPROCAL OF THE CONCENTRATION OF VASOPRESSIN IN THE SEROSAL. MEDIUM $\left(1 / \mathrm{V}_{\mathbf{s}}\right)$. Data taken from the middle graph. The open and closed circles (--O- , - - - identify the particular hemibladder of the pair in all three graphs. 


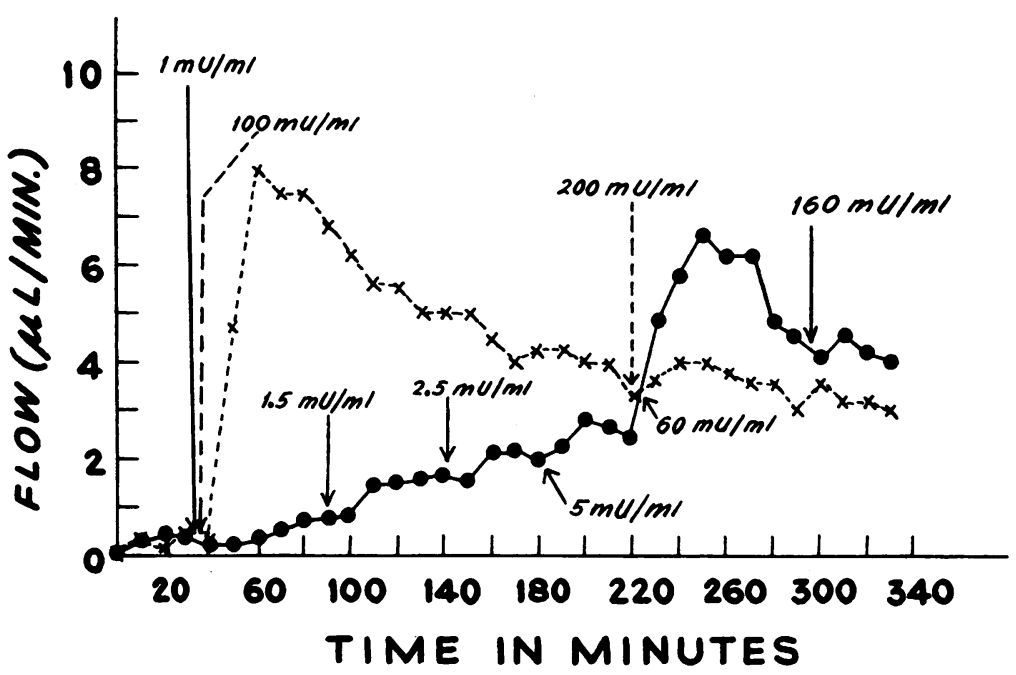

Fig. 3. THE EFFECT OF INCREMENTS IN THE CONCENTRATION OF VASOPRESSIN IN THE SEROSAL MEDIUM ON THE RATE OF OSMOTIC FLOW AS A FUNCTION OF TIME IN PAIRED HEMIBLADDERS. The hemibladder designated by the solid line (- - ) was exposed to small increments in the concentration of vasopressin until a saturation effect was achieved at $60 \mathrm{mU}$ per ml. Raising the concentration of vasopressin to $160 \mathrm{mU}$ per $\mathrm{ml}$ had no further effect. The hemibladder $(--X--)$ exposed initially to a saturating concentration of vasopressin (100 $\mathrm{mU}$ per $\mathrm{ml}$ ) showed a minimal response when the concentration of vasopressin was increased to $200 \mathrm{mU}$ per $\mathrm{ml}$.

(1/5 $\mathrm{Na}^{+}$Ringer's) was a $1 / 5$ dilution with water of serosal solution A. Mucosal solution A-C (1/10 choline Ringer's), consisting of $11.1 \mathrm{mM}$ choline chloride, $0.2 \mathrm{mM} \mathrm{KCl}, 0.2 \mathrm{mM} \mathrm{KHCO}_{3}, 0.3 \mathrm{mM} \mathrm{CaCl}$, and 0.6 $\mathrm{mM}$ glucose (osmolality $=0.023$ ), was used in the studies of water flow in the absence of net $\mathrm{Na}^{+}$transport. In the studies illustrated in Figure 8 the following solutions were used: Serosal solution B contained $111 \mathrm{mM}$ $\mathrm{NaCl}, 2.4 \mathrm{mM} \mathrm{NaHCO}, 8.0 \mathrm{mM} \mathrm{KCl}, 0.5 \mathrm{mM} \mathrm{MgCl}$, and $2.7 \mathrm{mM} \mathrm{CaCl}_{2}$ (osmolality $=0.235, \mathrm{pH}$ in air $=8.4$ ), and mucosal solution $B$ contained $24 \mathrm{mM} \mathrm{KCl}, 0.2 \mathrm{mM}$ $\mathrm{MgCl}_{2}$, and $0.5 \mathrm{mM} \mathrm{CaCl}_{2}$ (osmolality $=0.045$ ). Pitres$\sin ^{1}$ suspended in a buffer solution was used as the source of vasopressin and was added to the serosal medium in a volume of $0.5 \mathrm{ml}$ or less. Adenosine- $3^{\prime}, 5^{\prime}$ monophosphate ${ }^{2}$ was titrated with $\mathrm{NaOH}$ to a $\mathrm{pH}$ of 7.8 to 8.2 and delivered in a volume of $1 \mathrm{ml}$ or less.

The toads (Bufo marinus) were kept on wet earth for 2 to 14 days before being used. The osmolality of all solutions was measured with a Fiske freezing-point depression osmometer and $\mathrm{pH}$ with a Beckman model GS meter.

\section{Results}

Dose-response relationship

1) Vasopressin. Within 20 to 30 minutes after the bladders had been mounted, the rate of flow

1 Parke-Davis, Detroit, Mich.

2 Schwartz Bioresearch, Mt. Vernon, N. Y. averaged $0.2 \mu \mathrm{l}$ per minute for the smaller chambers and $1.0 \mu \mathrm{l}$ per minute for the larger chambers. After the addition of vasopressin to the serosal bathing medium and after a latent period of 5 to 20 minutes, the rate of osmotic flow increased to a peak value. The peak values were reached in 20 to 60 minutes (Figure 2). The time required to reach peak rates of flow tended to be inversely related to the concentration of hormone. As seen in Figures 2 and 3, increments in the concentration of vasopressin above threshold level $(1.0 \mathrm{mU}$ per $\mathrm{ml}$ for the small and $0.2 \mathrm{mU}$ per $\mathrm{ml}$ for the large chambers) ${ }^{3}$ led to progressive augmentation of osmotic flow. The degree of increase in the rate of flow, however, became successively less with each increment in vasopressin concentration, until a limiting maximal rate of flow was achieved. The pattern of response to stepwise increments in vasopressin concentration was the same whether the media were exchanged for fresh vasopressinfree solutions before addition of the next higher dose of vasopressin or the successive doses were superimposed in the original serosal medium

\footnotetext{
3 The symbol $\mathrm{mU}$ denotes milliunits based on the vasopressor assay.
} 


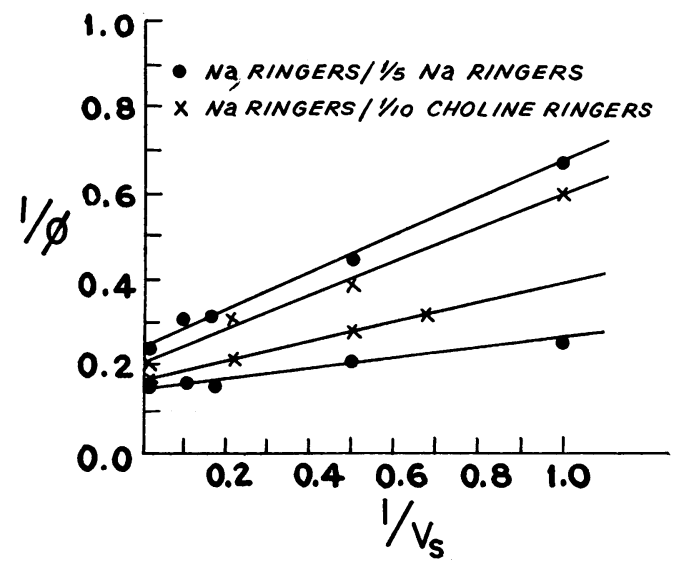

Fig. 4. The kinetics of the antidiuretic aCtion OF VASOPRESSIN IN THE PRESENCE AND ABSENCE OF $\mathrm{NA}^{+}$IN THE MUCOSAL MEDIUM. The reciprocal of osmotic flow at the peak of the response $(1 / \phi)$ is plotted as a function of the reciprocal of the concentration of vasopressin in the serosal medium $\left(1 / \mathrm{V}_{\mathrm{s}}\right)$. The solid circles (O) designate the studies using $1 / 5 \mathrm{Na}^{+}$Ringer's solution as the mucosal medium, and the crosses $(X)$ designate those using $1 / 10$ choline Ringer's solution (solution $\mathrm{A}-\mathrm{C})$ as the mucosal medium. In both sets of experiments, $\mathrm{Na}^{+}$Ringer's solution (solution $\mathrm{A}$ ) was used as the serosal medium.

(Figures 2 and 3 ). The characteristic features of saturation kinetics are illustrated by the reciprocal plot shown in Figure 2. Identical kinetics were obtained in the absence of net $\mathrm{Na}^{+}$ transport, which was assured by replacing all the $\mathrm{Na}^{+}$in the mucosal solution with choline (i.e., mucosal solution A-C) (Figure 4). Bentley (14) reported that the antidiuretic response to vasopressin was reduced by the substitution of choline for $\mathrm{Na}^{+}$in the mucosal medium, but Hays and Leaf ( 7 ) found that the antidiuretic activity of vasopressin was not $\mathrm{Na}^{+}$dependent.

2) Cyclic $A M P$. As shown in Figure 5, the time course of response to cyclic AMP, as well as the dose-response relationship, was indistinguishable from that of vasopressin. A plot of the reciprocal of the peak rate of flow against the reciprocal of the concentration of cyclic AMP also yielded a linear relationship (Figure 5).

\section{Relative potency}

The minimal concentration of vasopressin that regularly produced a significant increase in the rate of osmotic flow of water was 0.2 to $1.0 \mathrm{mU}$ per $\mathrm{ml}$ or $10^{-10}$ to $10^{-9} \mathrm{M}$, based on a potency of $450 \mathrm{U}$ per $\mathrm{mg}$ for pure arginine vasopressin. The threshold concentration for cyclic AMP was. between $10^{-3}$ and $10^{-4} \mathrm{M}$.

\section{Resistance}

The characteristic decay in the response to vasopressin and to cyclic AMP is shown in Figure 6. Shortly after the peak rate of flow was obtained, a progressive decline in flow set in. The development of resistance varied considerably from preparation to preparation but was always greatest after the maximal rate of flow had been elicited. The correlation between the concentration of hormone and the velocity of the resistance reaction is also apparent in the data of Karlin (13). Resistance was clearly not a consequence of destruction of the hormone by the bladder, since the addition of saturating quantities of vasopressin to the inhibited system failed to elicit a further increase in its permeability to water (Figure 3). Resistance to the action of vasopressin is not a result of time-dependent in vitro deterioration of the vasopressin-sensitive element. As shown in Figure 3, an equal concentration of hormone yielded an equivalent maximal response 220 minutes after the hemibladder had been

TABLE I

Reversibility of self-induced resistance to vasopressin and to cyclic AMP

\begin{tabular}{|c|c|c|c|c|c|}
\hline \multirow{2}{*}{$\begin{array}{l}\text { No. of } \\
\text { experi- } \\
\text { ments }\end{array}$} & \multirow[b]{2}{*}{ Agent } & \multirow[b]{2}{*}{ Concentration } & \multicolumn{3}{|c|}{ Osmotic flow* } \\
\hline & & & First peak & Final & Second peak \\
\hline & & & \multicolumn{3}{|c|}{$\mu l / \operatorname{minute}$} \\
\hline $\begin{array}{l}7 \\
8\end{array}$ & $\begin{array}{l}\text { Vasopressin } \\
\text { Cyclic AMP }\end{array}$ & $\begin{array}{l}62.5 \mathrm{mU} / \mathrm{ml} \\
6.5 \times 10^{-3} \mathrm{M}\end{array}$ & $\begin{array}{l}7.2 \pm 0.7 \\
4.7 \pm 0.4\end{array}$ & $\begin{array}{l}3.1 \pm 0.4 \\
2.2 \pm 0.2\end{array}$ & $\begin{array}{l}6.2 \pm 0.7 \\
2.4 \pm 0.3\end{array}$ \\
\hline
\end{tabular}

* Mean \pm standard error of the mean. The designation "final" refers to the value obtained just before the media were replaced with fresh hormone-free or nucleotide-free media (see Figure 6). 


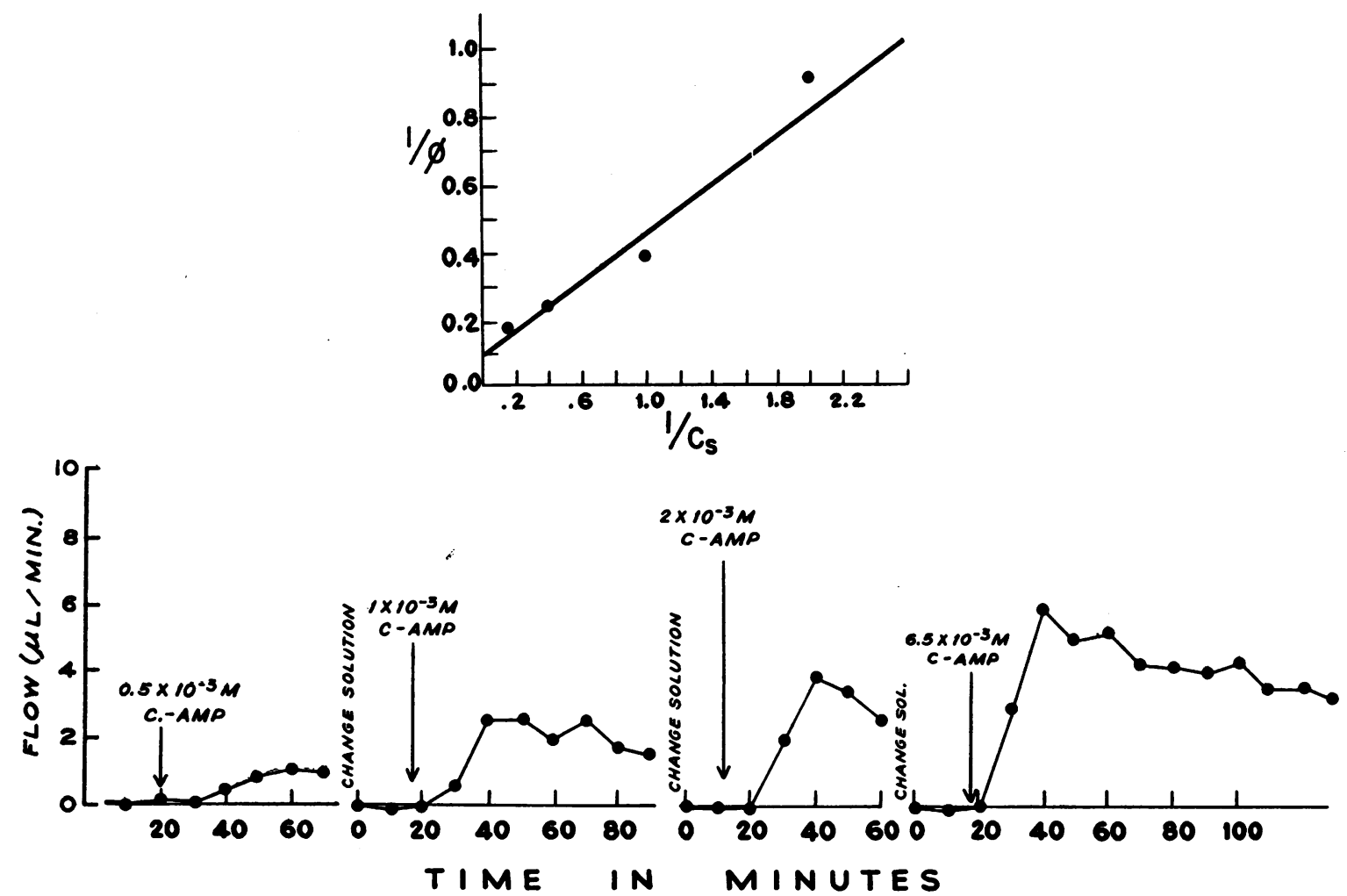

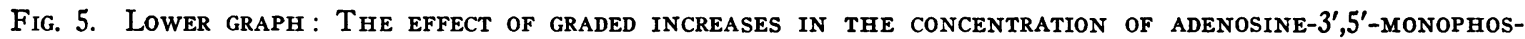
PHATE (C-AMP) ON THE RATE of osmotic Flow AS A Function of time. The time of addition to the serosal medium is indicated by the arrow. UPPER GRAPH: THE RECIPROCAL OF THE RATE OF OSMOTIC FLOW AT THE PEAK OF THE RESPONSE $(1 / \phi)$ AS A FUNCTION OF THE RECIPROCAL OF THE CONCENTRATION OF CYCLIC AMP IN THE SEROSAL MEDIUM $\left(1 / \mathrm{C}_{\mathrm{s}}\right)$. Data taken from the lower graph.

mounted, at a time when the paired hemibladder showed well-developed resistance.

\section{Reversal of resistance}

The initial state of minimal permeability could be restored by removal and washout of the media after resistance was well developed. Reintroduction of the same quantity of vasopressin produced a second response of comparable magnitude (Figure 6 and Table I). In each instance, however, the second peak was lower than the first peak, and the average difference of $1.0 \mu l$ per minute was statistically significant by the paired method. These results indicate that there was some element of irreversibility in the resistance to vasopressin. The same maneuver carried out with cyclic AMP resulted in restoration of the state of minimal permeability but little or no reversal of the resistance to cyclic AMP (Figure 6 and Table I).
Th possible existence of a common mechanism responsible for the resistance induced by either vasopressin or cyclic AMP was ruled out by cross experiments (Figure 7 and Table II). After the

TABLE II

Effects of combinations of vasopressin and cyclic $A M P$ on osmotic flow

\begin{tabular}{ccccc}
\hline \hline Period & $\begin{array}{c}\text { Vaso- } \\
\text { pressin }\end{array}$ & $\begin{array}{c}\text { Cyclic } \\
\text { AMP }\end{array}$ & Flow* & p ${ }^{*}$ \\
\hline & $m U / m l$ & $\times 10^{-3} M$ & $\mu l / m i n u t e$ & \\
A & 62.5 & 0 & $5.7 \pm 0.5$ (peak) & \\
B & 125 & 0 & $3.1 \pm 0.5$ (final) & $<0.025$ \\
C & 125 & 7 & $4.7 \pm 0.7$ (peak) & \\
A & 0 & 9 & $4.5 \pm 0.4$ (peak) & \\
B & 0 & 19 & $3.7 \pm 0.3$ (final) & $<0.01$ \\
C & 62.5 & 19 & $6.5 \pm 0.6$ (peak) & \\
& & & &
\end{tabular}

* Mean \pm standard error of the mean obtained in two sets of six experiments. The maximal or "peak" flow was recorded for periods A and C. "Final" refers to the value of osmotic flow at the end of period $B$ (see Figure 7)

+ For periods $B$ versus $C$ 


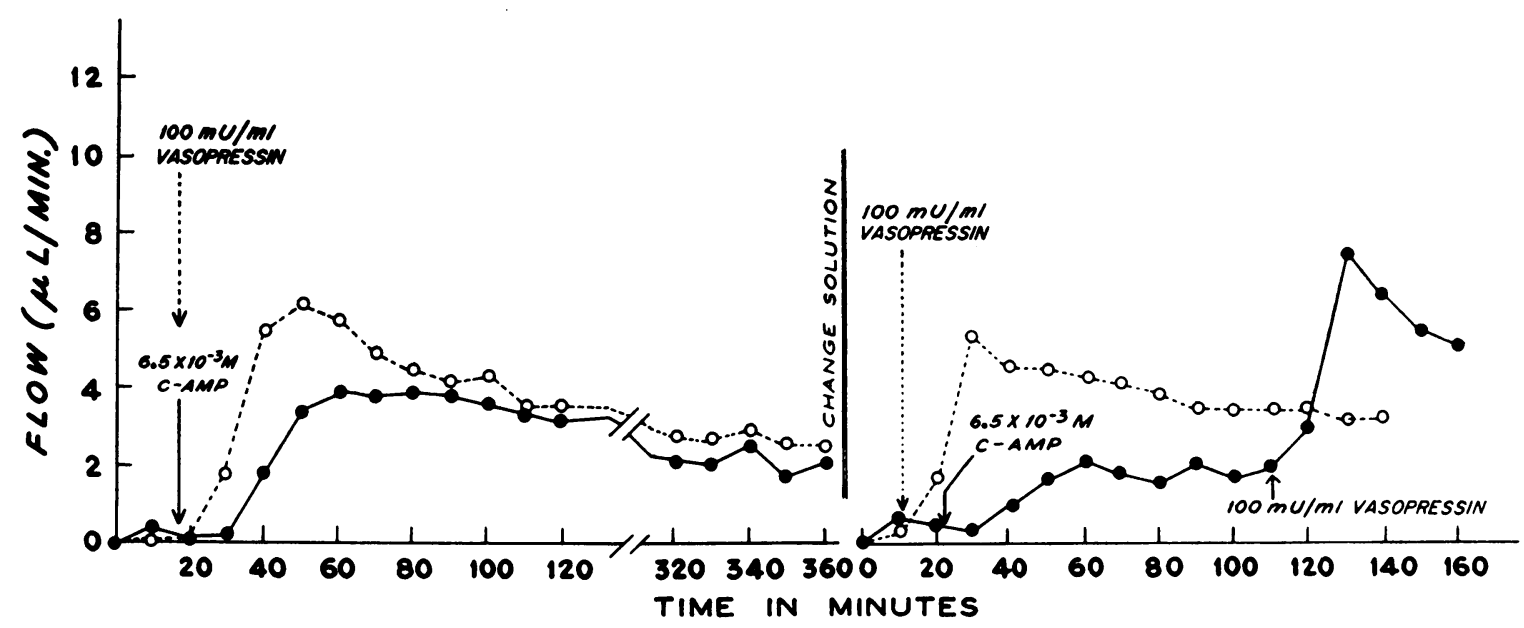

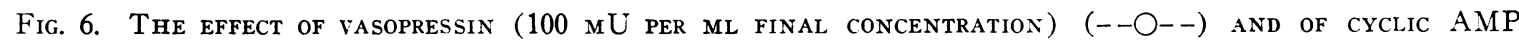
$\left(6.5 \times 10^{-8} \mathrm{M}\right)\left(-\mathrm{O}_{-}\right)$ON THE RATES OF OSMOTIC FLOW AFTER WELL-DEVELOPED RESISTANCE HAD BEEN INTERRLPTED BY REPLACEMENT OF THE SEROSAL SOLUTIONS WITH HORMONE-FREE MEDIA. Note the response to vasopressin of the hemibladder resistant to cyclic AMP.

maximal response to saturating concentrations of cyclic AMP and the decay of the response to about $80 \%$ of the peak value, the addition of saturating quantities of vasopressin to the serosal media resulted in an increased rate of osmotic flow. The reverse experiment in which saturating quantities of cyclic AMP were added after resistance was well developed also resulted in a significant increase in the rate of flow (Table II).

The reversal of the resistance to vasopressin after washout and restoration of the base-line low level of permeability may have resulted from regeneration of a critical component in the receptor cells that had become rate-limiting. Eight studies were executed, however, which did not support this interpretation. Figure 8 is a representative example of these studies. After resistance had been well developed, the serosal solution was removed and immediately replaced with fresh solution containing the original concentration of hormone. Reversal of resistance occurred without a period of recovery at low permeability levels, indicating that resistance could be attributed in large part to the accumulation of a diffusible inhibitor.

\section{Discussion}

A kinetic model of the action of neurohypophyseal hormones on the osmotic flow of water can be deduced from two findings : 1) The change in re- sistance to osmotic flow was proportional to the concentration of hormone in the serosal medium, but the resulting increase in flow approached a limiting maximal value. 2) The increase in osmotic flow induced by vasopressin was reversed by replacement of the serosal medium with hormone-free solution. A satisfactory but not necessarily correct kinetic model can be constructed, as proposed by Hollander and colleagues (12), under the following set of assumptions: 1) The concentration of vasopressin or its intermediate at the receptor sites (V) is linearly proportional to the concentration of vasopressin in the serosal medium $\left(\mathrm{V}_{\mathbf{s}}\right)$. Then,

$$
\mathrm{V}=\alpha \mathrm{V}_{\mathbf{s}},
$$

where $\alpha$ is the coefficient of distribution in the steady state.

2) The active intermediate (V) reacts reversibly with independent receptor sites $(R)$ to produce a complex $\overline{\mathrm{VR}}$, and at equilibrium,

$$
\mathrm{K}=\frac{\overline{\mathrm{VR}}}{\mathrm{V} \cdot \mathrm{R}},
$$

where $\mathrm{K}$ is the association constant for the reaction $\mathrm{V}+\mathrm{R} \rightleftharpoons \overline{\mathrm{VR}}$.

3) Ussing [as quoted by Hollander and colleagues (12)] proposed that each complex $\overline{\mathrm{VR}}$ gives rise to a pore, or in more general terms a locus of decreased resistance to osmotic flow. 


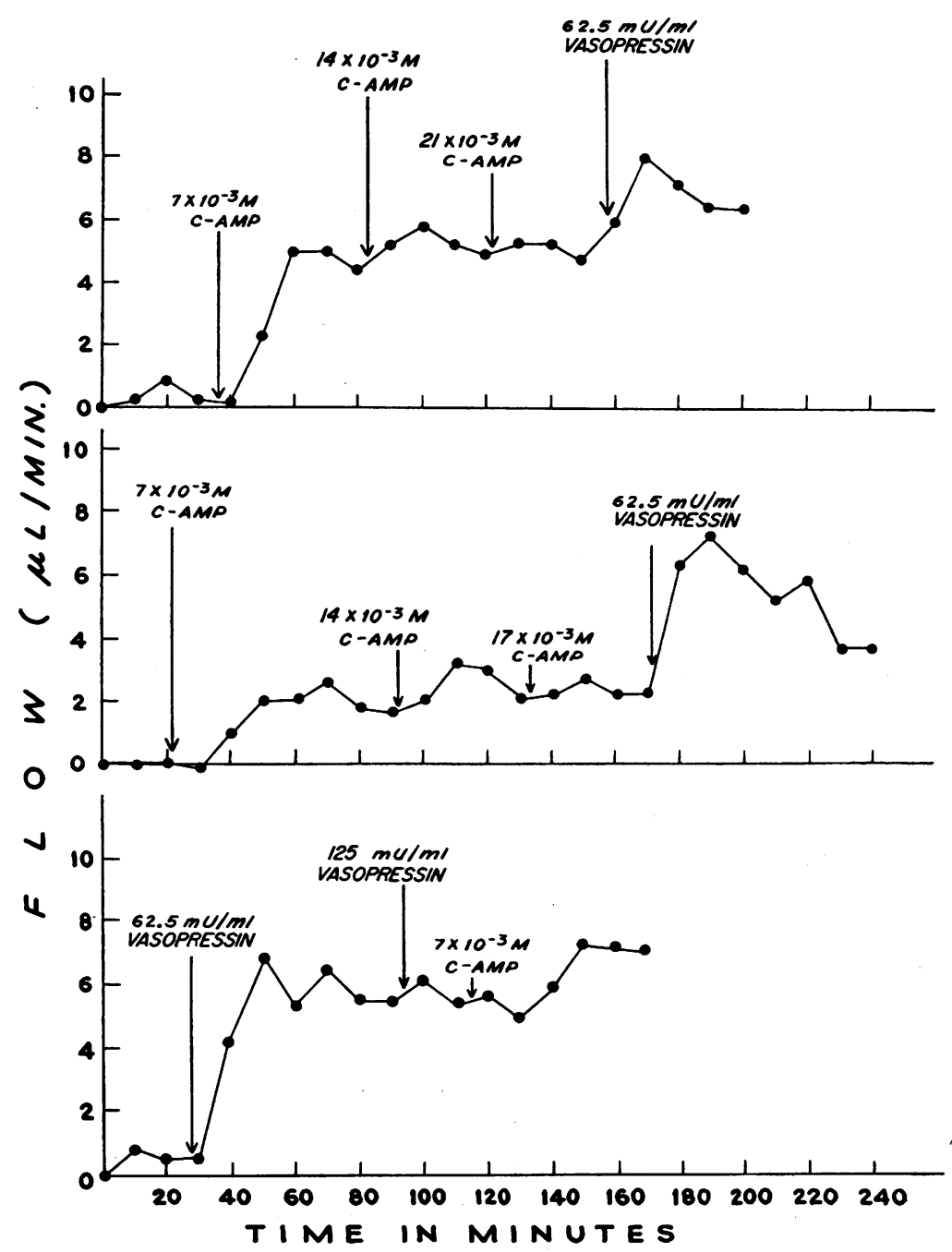

Fig. 7. LOWER GRAPH: The EFFECT OF CyClic AMP (FINAL CONCENTRATION IN THE SEROSAL MEDIUM, $7 \times 10^{-8} \mathrm{M}$ ) ON THE RATE OF OSMOTIC FLOW AFTER THE ADDITION OF SUCCESSIVE SATURATING QUANTITIES OF VASOPRESSIN. MidDle AND UPPER GRAPHS: THE EFFECT OF VASOPRESSIN (FINAL CONCENTRATION IN THE SEROSAL MEDIUM, 62.5 MU PER ML) ON THE RATE OF OSMOTIC FLOW AFTER THE ADDITION OF SUCCESSIVE SATURATING QUANTITIES OF CYCLIC AMP.

Consequently,

$$
\phi=\beta \cdot \overline{\mathrm{VR}},
$$

where $\phi$ is the rate of flow at a constant difference in osmotic pressure and $\beta$ is an empirical coefficient.

4) To complete the derivation, it is also necessary to assume that the total number of receptor sites are conserved.

These assumptions yield the following relation- ship :

$$
\frac{1}{\phi}=\frac{\mathrm{k}}{\mathrm{V}_{\mathrm{s}}}+\frac{1}{\phi_{\mathrm{m}}}
$$

where $\phi_{m}$ denotes the maximal rate of flow and $\mathrm{k}=1 /\left(\boldsymbol{\alpha} \cdot \mathrm{K} \cdot \phi_{\mathrm{m}}\right)$. This result is formally equivalent to a Langmuir adsorption isotherm (15). In essence Hollander and associates (12) presented the same hypothesis for the action of vasopressin in vivo. They found a linear dependence of the 


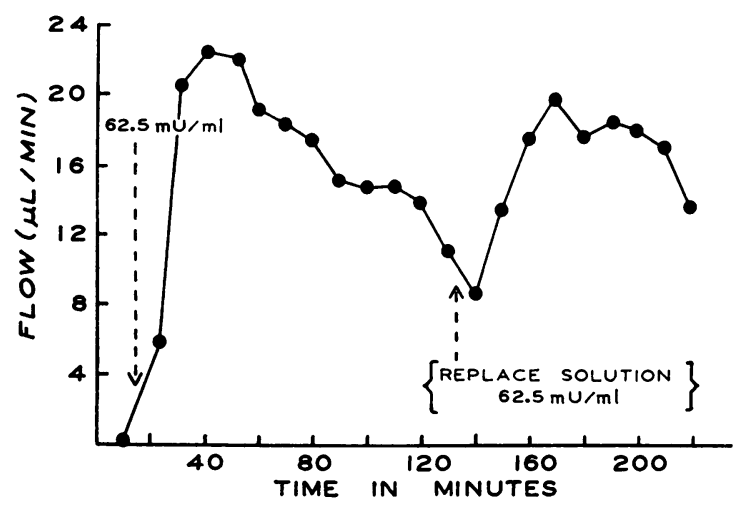

Fig. 8. ThE EFFECT OF DIRECT REPLACEMENT OF THE SEROSAL MEDIUM WITH A FRESH SOLUTION CONTAINING VASOPRESSIN (62.5 MU PER ML) AFTER RESISTANCE WAS WELL DEVELOPED.

reciprocal of the vasopressin-dependent increment in the rate of reabsorption of water by the rat kidney (inferred from the difference between the clearance of free water during maximal water diuresis and its clearance during a constant infusion of vasopressin) on the reciprocal of the rate of infusion of vasopressin. We found a similar relationship in vitro (Figures 2 and 4). Some additional conclusions, however, can be drawn from our observations. The concentration of vasopressin at the serosal surface of the receptor cell, rather than the action of an intermediate produced by some other organ such as the liver, determines the effect. The possibility that local changes in blood flow influenced the kinetics of the antidiuretic response is eliminated by our studies. It is also apparent that although vasopres$\sin$ accelerates the rate of active transport of $\mathrm{Na}^{+}$ $(3,16)$, the kinetics of the antidiuretic response are independent of effects on $\mathrm{Na}^{+}$transport (Figure 4).

A puzzling feature of the kinetics of the action of vasopressin concerns the role of cyclic AMP as an intermediate. Equation 4 is derived on the assumption of a linear dependence of the concentration of the active intermediate at the receptor sites on the concentration of vasopressin in the medium. Orloff and Handler (9) proposed that vasopressin activates adenyl cyclasemediated conversion of ATP to cyclic AMP. For a complex sequence of steps such as vasopressin + enzyme $\rightarrow$ activated enzyme $+\mathrm{ATP} \rightarrow$ cyclic AMP, one would not necessarily expect a linear relationship between the concentration of vasopressin in the external medium and the concentration of cyclic AMP at the receptor site. Since all of the steps in the sequence of reactions leading to a change in the properties of the mucosal face of the epithelial cells are not known, the kinetics of the over-all reaction cannot be derived explicitly. Consequently, it is not possible to use the kinetic argument alone as a test of the cyclic AMP hypothesis.

The form of the kinetics of the antidiuretic action of cyclic AMP is indistinguishable from that of vasopressin (Figures 2 and 5). The minimal concentration in the serosal medium necessary to produce a consistent increase in osmotic flow, however, is far greater for cyclic AMP $\left(\sim 10^{-4}\right.$ $\mathrm{M})$ than for vasopressin $\left(\sim 10^{-10} \mathrm{M}\right)$. In broken-cell preparations the nucleotide is effective at concentrations of $\sim 10^{-8} \mathrm{M}$ (17), suggesting that inactivation of cyclic AMP by cyclic nucleotide phosphodiesterase may reduce the concentration that is achieved in the intact toad bladder. Another feature that needs explanation is the ability of vasopressin to produce a further increase in water flow after saturation with cyclic AMP. It might be inferred from these observations that the mucosal cell surface of the toad bladder contains two classes of sites and that vasopressin activates both classes by stimulating the formation of intracellular cyclic AMP as well as by another mechanism. The relatively small effect of cyclic AMP on the vasopressin-saturated system observed in our experiments (Figure 7 and Table II) is also compatible with this explanation. An alternative explanation, however, is provided by some of our recent observations on the $\mathrm{pH}$ dependence of the antidiuretic action of cyclic AMP. The optimum $\mathrm{pH}$ for vasopressin is greater than 8.0, whereas it is 7.0 for cyclic AMP (18). At the $\mathrm{pH}$ of the Ringer's solution $(\sim 8.4)$ used in the present experiments, vasopressin would be acting at its optimum $\mathrm{pH}$, whereas cyclic AMP would be constrained.

Karlin (13) recently reported that the development of progressive resistance to the antidiuretic action of oxytocin in the urinary bladder of the toad does not result from irreversible changes in the epithelium or inactivation of the oxytocin in the medium but rather from the accumulation of a poorly dialyzable inhibitor in the serosal medium. 
Our results confirm his findings in large measure. In addition, we found that resistance develops to the action of both vasopressin and cyclic AMP when these agents are present in the media continuously. Resistance to vasopressin was reversed in large part simply by replacing the serosal solution with a fresh solution containing the same concentration of hormone (Figure 8). Removal of the original serosal solution and then reintroduction of the original solution does not reverse acquired resistance so that the reversal effect of fresh solutions cannot be attributed to mechanical stimulation (13). Resistance to cyclic AMP, however, was not reversed by replacing the serosal solution with a fresh solution of cyclic AMP after allowing the permeability to water of the toad bladder to return to resting levels (Figure 6). The addition of either vasopressin or cyclic AMP to the serosal medium after resistance to the other agent was well developed resulted in a significant increase in osmotic flow (Table II). The response to vasopressin of the cyclic AMP-resistant system was greater than the response to cyclic AMP of the vasopressin-resistant system. These results indicate that separate pathways are involved in the development of resistance to these agents and that neither type of resistance involves a change at the locus of decreased resistance to osmotic flow in the mucosal face of the epithelial cells of the bladder. The irreversibility of cyclic AMP-induced resistance to cyclic AMP is particularly mysterious in view of the responsiveness of this system to vasopressin.

\section{Summary}

A volume chamber that permits continuous measurement of the net flow of water across the isolated urinary bladder of the toad was developed and used in the present studies to characterize the response to vasopressin and cyclic AMP. The antidiuretic response to both agents gave the same type of saturation kinetics, consistent with the model previously proposed by Hollander and associates (12). In view of the strong evidence in support of the cyclic AMP theory of the action of vasopressin, it was puzzling to find that the development of spontaneous resistance to either agent alone did not block a significant response to the other. In addition, vasopressin- induced resistance to vasopressin was almost completely reversible, whereas cyclic AMP-induced resistance to cyclic AMP was not reversible under the conditions of the present studies.

\section{Acknowledgments}

Mr. Glenn Downes, Miss Ella Highland, and Mrs. Le Moyne Mueller provided able technical assistance in the course of this study.

\section{References}

1. Novelli, A. Lóbulo posterior de hipófisis e imbibición de los batraciós. II. Mecanismode su acción. Rev. Soc. argent. Biol. 1936, 12, 163.

2. Sawyer, W. H. Effect of posterior pituitary extract on permeability of frog skin to water. Amer. J. Physiol. 1951, 164, 44.

3. Fuhrman, F. A., and H. H. Ussing. A characteristic response of the isolated frog skin potential to neurohypophysial principles and its relation to the transport of sodium and water. J. cell. comp. Physiol. 1951, 38, 109.

4. Bentley, P. J. The effects of neurohypophysial extracts on water transfer across the wall of the isolated urinary bladder of the toad Bufo marinus. J. Endocr. 1958, 17, 201.

5. Koefoed-Johnsen, V., and H. H. Ussing. The contributions of diffusion and flow to the passage of $\mathrm{D}_{2} \mathrm{O}$ through living membranes. Effect of neurohypophyseal hormone on isolated anuran skin. Acta physiol. scand. 1953, 28, 60.

6. Andersen, B., and H. H. Ussing. Solvent drag on non-electrolytes during osmotic flow through isolated toad skin and its response to antidiuretic hormone. Acta physiol. scand. 1957, 39, 228.

7. Hays, R. M., and A. Leaf. Studies on the movement of water through the isolated toad bladder and its modification by vasopressin. J. gen. Physiol. 1962, 45, 905.

8. Hays, R. M., and A. Leaf. The state of water in the isolated toad bladder in the presence and absence of vasopressin. J. gen. Physiol. 1962, 45, 933.

9. Orloff, J., and J. S. Handler. The similarity of effects of vasopressin, adenosine- $3^{\prime}, 5^{\prime}$-phosphate (cyclic AMP) and theophylline on the toad bladder. J. clin. Invest. 1962, 41, 702.

10. Handler, J. S., and J. Orloff. Activation of phosphorylase in toad bladder and mammalian kidney by antidiuretic hormone. Amer. J. Physiol. 1963, 205, 298.

11. Brown, E., D. L. Clarke, V. Roux, and G. H. Sherman. The stimulation of adenosine $3^{\prime}, 5^{\prime}$-mono- 
phosphate production by antidiuretic factors. J. biol. Chem. 1963, 238, PC 852.

12. Hollander, W., Jr., T. F. Williams, C. C. Fordham III, and L. G. Welt. A study of the quantitative relationship between antidiuretic hormone (vasopressin) and the renal tubular reabsorption of water. J. clin. Invest. 1957, 36, 1059.

13. Karlin, A. The in vitro release by the toad bladder of an inhibitor of oxytocin. Biochem. biophys. Res. Commun. 1963, 11, 44.

14. Bentley, P. J. The effects of ionic changes on water transfer across the isolated urinary bladder of the toad Bufo marinus. J. Endocr. 1959, 18, 327.
15. Langmuir, I. The constitution and fundamental properties of solids and liquids. Part I. Solids. J. Amer. chem. Soc. 1916, 38, 2221.

16. Leaf, A. Some actions of neurohypophyseal hormones on a living membrane. J. gen. Physiol. 1960, 43 (suppl. 1), 175.

17. Rall, T. W., and E. W. Sutherland. Formation of a cyclic adenine ribonucleotide by tissue particles. J. biol. Chem. 1958, 232, 1065.

18. Gulyassy, P. F., and I. S. Edelman. The $\mathrm{pH}$ dependence of the antidiuretic action of vasopressin in vitro. Proc. Second Int. Cong. Nephrology, Prague, 1963. In press. 